\section{Diffuse meningeal thickening associated with pleural mesothelioma}

\author{
J B Murray, J B Neilly, D Hadley, \\ F Moran, M McKean
}

\begin{abstract}
A case of pleural mesothelioma with diffuse spinal meningeal thickening as shown by magnetic resonance imaging is reported.
\end{abstract}

Diffuse spinal malignancy has not been described in malignant mesothelioma. We report the association of histologically proved malignant pleural mesothelioma with diffuse spinal meningeal thickening by magnetic resonance imaging.

\section{Case report}

A 48 year old man, a roofing contractor, presented in May 1987 with bilateral pleural effusions (protein content $40 \mathrm{~g} / \mathrm{l}$ ). He said that he had occasionally worked with asbestos tiles; but the initial investigations failed to produce the diagnosis. Aspiration of the effusions was carried out but they recurred repeatedly.

In July 1987 he developed severe localised low back pain at the lumbosacral junction, radiating into the right groin and testes and extending to the anterior aspect of both thighs. The erythrocyte sedimentation rate was $70 \mathrm{~mm}$ in one hour; a haematological screen and biochemical investigation gave normal results. Urinary retention occurred on two occasions.

Plain radiography of the spine and pelvis showed minor degenerative disease and the isotope bone scan was normal. Lumbar puncture resulted in a dry tap and lumbar myelography was unsuccessful. Magnetic resonance imaging showed diffuse thickening of the spinal meninges with obliteration of the subarachnoid space along the length of the thoracic and lumbar spine (figure). The cauda equina appeared to be "matted" and this appearance extended caudally to the spinal hiatus. Cisternal puncture yielded a small amount of clear cerebrospinal fluid containing normal concentrations of protein $(0.18 \mathrm{~g} / \mathrm{l})$ and glucose $(4.8 \mathrm{mmol} / \mathrm{l})$. A direct cervical myelogram showed an irregular theca with a block to the caudal flow of contrast at the $\mathrm{C} 4$ level.

Examination of the pleural fluid showed numerous benign mesothelial cells and histiocytes. The closed pleural biopsy appearances were normal. There was no bronchoscopic abnormality, but left sided thoracoscopy showed multiple nodules across the visceral and parietal pleural surfaces. Histological examination of the pleural biopsy specimen showed the presence of malignant mesothelioma. At this stage he was requiring large doses of morphine to control the pain in his lower back and his legs. In October 1987 he developed wasting of the proximal muscles in the upper limbs and complained of severe pains in the mid cervical spine region posteriorly. Before radiotherapy could be arranged he developed quadriparesis with signs of cervical cord compression. He died several days later. Permission for postmortem examination was not granted.

\section{Discussion}

The occurrence of haematogenous disseminated metastases from malignant mesothelioma of the pleura are well recognised. ${ }^{1-3}$ Metastases to the central nervous system, however, are rare findings, with only 16 cases of confirmed brain lesions reported. ${ }^{3-6}$ Direct extension of the tumour into the spinal column and invasion of the meninges have been recorded.

This patient had no predisposition to arachnoiditis secondary to previous surgery or myelography. The loss of the subarachnoid space and "matting" of the cauda equina in association with the progressive neurological symptoms would be in keeping with diffuse metastases, though unfortunately we could

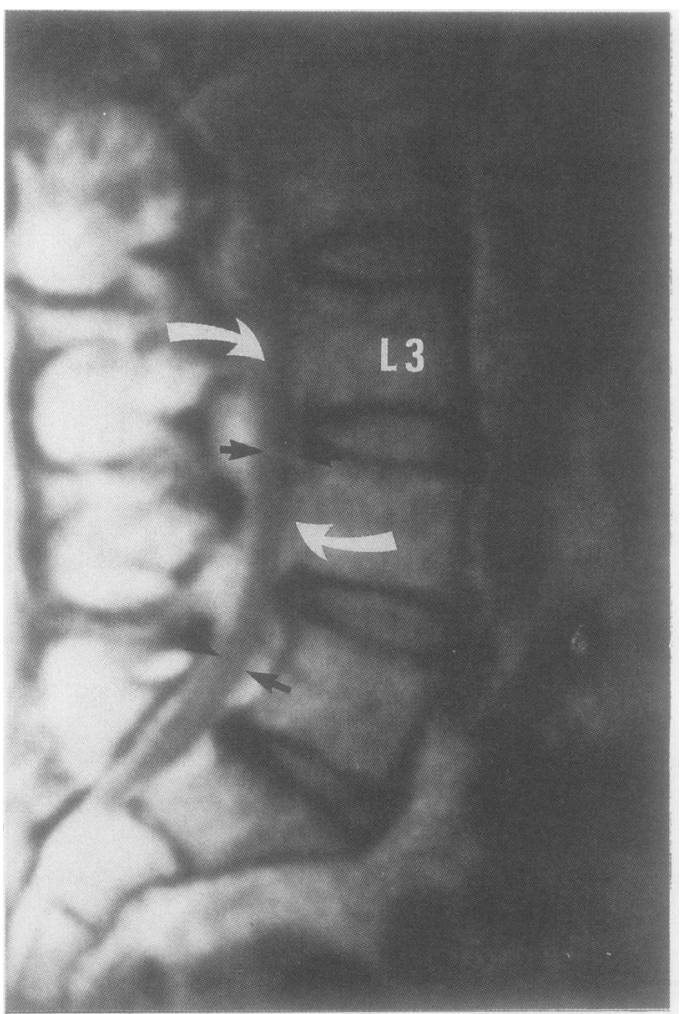

Magnetic resonance image of the lumbar spine: midline $T 1$ weighted ( $S E 700 / 40$ ) $8 \mathrm{~mm}$ sagittal section (obtained with a surface receiver coil) showing thickened dura and meninges (curved arrows) with matted cauda equina (straight arrows) to the sacral cul de sac. 
not confirm this as permission for necropsy was refused.

The association in this patient of histologically proved pleural mesothelioma and diffuse meningeal thickening with loss of the subarachnoid space and "matting" of the cauda equina, as shown by magnetic resonance imaging, is unusual. To our knowledge no similar case has been described on the basis of magnetic resonance imaging.
1 Urschel HC, Paulson DL. Mesothelioma of the pleura. Ann Thoracic Surg 1965;1:559-74.

2 Oels MC, Harrison EG, Carr DT, Bernatz PE. Diffuse malignant mesothelioma of the pleura. Chest 1971;60: malignant

3 Roberts GH. Distant visceral metastases in pleural mesothelioma. Br J Dis Chest 1976;70:246-50.

4 Walters KL, Martinez AJ. Malignant fibrous mesothelioma. Acta Neuropathol Berlin 1975;33:173-7.

5 Schwechheimer $\mathrm{K}$, Butzengeiger $M$. Brain metastases in malignant fibrous mesothelioma. Acta Neuropathol Berlin 1983;60:301-4.

6 Kaye JA, Wang AM, Joachim CL, et al. Malignant mesothelioma with brain metastases. Am J Med 1986;80:95-7.

7 Semb G. Diffuse malignant pleural mesothelioma. Acta Chir Scand 1963;126:78-91. 